\title{
Polygala tenuifolia extract inhibits lipid accumulation in 3T3-L1 adipocytes and high-fat diet-induced obese mouse model and affects hepatic transcriptome and gut microbiota profiles
}

\author{
Chun-Chung Wang ${ }^{\mathrm{a}, \mathrm{b}}$, Jui-Hung Yen ${ }^{\mathrm{b}}$, Yi-Cheng Cheng ${ }^{\mathrm{b}}$, Chia-Yu Lin ${ }^{\mathrm{b}}$, Cheng-Ta Hsieh ${ }^{\mathrm{b}}$, Rung-Jiun Gau ${ }^{\mathrm{b}}$, \\ Shu-Jiau Chiou ${ }^{b}$ and Hwan-You Chang ${ }^{a}$

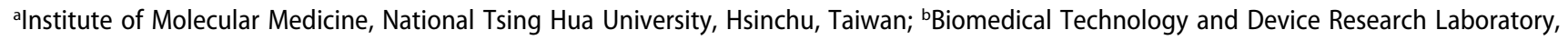 \\ Industrial Technology Research Institute, Hsinchu, Taiwan
}

\begin{abstract}
Obesity, the excessive accumulation of lipids in the body, is closely associated with many prevalent human disorders. Continued efforts to identify plant extracts that exhibit anti-obesity effects have drawn much attention. This study investigated whether a Polygala tenuifolia extract (PTE) possesses antiobesity activity and how PTE may affect liver gene expression and gut microbiota. We used 3T3-L1 adipocytes and a high-fat diet-induced obese mouse model to determine the effects of PTE on lipid accumulation. Next-generation sequencing analysis of liver gene expression and gut microbiota profiles following PTE treatment were conducted to elucidate possible mechanisms. We found that treatment of fully differentiated 3T3-L1 adipocytes with PTE inhibited lipid accumulation in the cells through reducing lipid formation and triglyceride content and by increasing lipase activity. No cytotoxicity was observed from the PTE treatment. After 5 weeks of treatment with PTE, the increased body weight, elevated serum triglyceride content, and liver steatosis in the high-fat diet-induced obese mice were each reduced. Liver transcriptomic analysis revealed that expression of genes involved in lipid and cholesterol metabolism was significantly altered. The low-grade chronic inflammation of obesity caused by a high-fat diet was also decreased after PTE treatment. In addition, treatment with PTE improved the relatively low Bacteroidetes/Firmicutes ratio in the gut of high-fat diet-fed mice through enrichment of the Proteobacteria population and reduction of the Deferribacteres population. In conclusion, treatment with PTE inhibited lipid accumulation by inducing the expression of the master transcription factor PPARa, attenuated the low-grade chronic inflammation of obesity, and also altered gut microbiota profiles. These results indicate that PTE has the potential to be developed into an anti-obesity food supplement and therapy.
\end{abstract}

\begin{abstract}
Abbreviations: Abcg5: ATP-binding cassette subfamily G member 5; ALT: alanine aminotransferase; AMPK: adenosine monophosphate-activated protein kinase; AST: aspartate aminotransferase; B/F: Bacteroidetes to Firmicutes [ratio]; C/EBPa: CCAAT/enhancer-binding protein alpha; CR: creatinine; Cyp51: cytochrome P450 family 51; DMEM: Dulbecco's modified Eagle's medium; Fabp5: fatty acidbinding protein 5; FBS: fetal bovine serum; Fdps: farnesyl diphosphate synthase; Glc: Glucose; HFD: high-fat diet; GO: gene ontology; HPRT: hypoxanthine guanine phosphoribosyl transferase; IBMS: 3isobutyl-1-methylxanthine; Idi1: isopentenyl-diphosphate delta isomerase 1; IL-1 $\beta$ : interleukin-1-beta; Lpin1: phosphatidic acid phosphohydrolase; LPS: lipopolysaccharide; Mvd: mevalonate diphosphate decarboxylase; ND: normal diet; OTU: operational taxonomic units; Pcsk9: proprotein convertase subtilisin/kexin 9; Pctp: phosphatidylcholine transfer protein; PPARa: peroxisome proliferator-activated receptor alpha; PPARY: peroxisome proliferator-activated receptor gamma; PTE: Polygala tenuifolia extract; Saa1: serum amyloid A1; SD: standard deviation; SEM: standard error of the mean; Serpina12: serpin family member 12; Sqle: squalene monooxygenase; SREBP1C: sterol regulatory element-binding protein 1C; TCHO: total cholesterol; TG: triglyceride
\end{abstract}

\section{ARTICLE HISTORY}

Received 18 May 2017

Accepted 10 September 2017

\section{KEYWORDS}

Obesity; lipid accumulation; liver transcriptome; Polygala tenuifolia; gut microbiota

\section{Introduction}

Obesity is defined by the World Health Organization as a body mass index $>30 \mathrm{~kg} / \mathrm{m}^{2}$ [1]. In 2014, around 600 million people worldwide were estimated to be obese [2]. Obesity is associated with many common diseases, such as nonalcoholic fatty liver, hypertension, osteoarthritis, cardiovascular diseases, stroke, type 2 diabetes, and various cancers [3-6]. Due to the medical importance of obesity, considerable research has been devoted to developing appropriate treatments. Although several drugs have been approved by US Food and Drug Administration to treat 
obesity, their efficacy is often low and side effects are common $[7,8]$. Therefore, there is a great need for a welltolerated treatment for obesity that has minimal side effects.

Recently, extracts from several plants have been reported to have anti-obesity effects. These plants include Adenophora triphylla [9], Cudrania tricuspidata [10], Crinum asiaticum [11], Hibiscus sabdariffa [12], green coffee bean [13], and Tripterygium wilfordii [14]. Several active anti-obesity ingredients present in plants have also been identified, such as saponins from Glycyrrhiza uralensis [15] and Astragalus propinquus [16], polysaccharides from Lycium barbarum [17,18] and Schisandra chinensis [18], and polyphenols from Crataegus pinnatifida Bunge [19]. These plant extracts and natural compounds have considerable potential to be further developed into effective therapies for obesity [20].

Polygala tenuifolia, also called Yuanzhi, is a traditional Chinese herbal medicine widely used in Asian countries to treat inflammation [21], depression [22], amnesia, neurasthenia, and insomnia, as well as for the prevention of dementia and memory loss $[23,24]$. Two herbal mixtures containing $P$. tenuifolia, $\mathrm{SH} 21 \mathrm{~B}$ and $\mathrm{KBH}-1$, have been used to treat obesity in Korea [25]. SH21B was demonstrated to reduce fat accumulation in mice by inhibiting the expression of transcription factors involved in adipogenesis, such as peroxisome proliferator-activated receptor gamma (PPAR $\gamma)$, CCAAT/enhancer-binding protein alpha $(\mathrm{C} / \mathrm{EBP} \alpha)$, and sterol regulatory element-binding protein 1C (SREBP1C) [25]. The other herbal treatment, $\mathrm{KBH}-1$, reduced lipid accumulation in rats by upregulating the adenosine monophosphate-activated protein kinase (AMPK) pathway, which resulted in the inhibition of fatty acid synthesis and adipogenic transcription factor PPAR [26,27]. However, the mechanism through which P. tenuifolia extract (PTE) alone inhibits fat accumulation has not been determined.

In the last decade, gut microbiota has been shown to be an important factor in metabolic dysregulation, including obesity and diabetes $[28,29]$. Among the four predominant bacterial phyla present in humans and mice [30] - namely Bacteroidetes, Firmicutes, Actinobacteria, and Proteobacteria - significant differences in the ratio of Bacteroidetes to Firmicutes (B/F) between obese and lean humans and rodents have been noted [31,32]. A relatively lower population of Bacteroidetes with a corresponding increase in Firmicutes was noted in some studies when comparing obese and lean individuals [33,34]. However, shifts to lower $\mathrm{B} / \mathrm{F}$ ratios have also been reported elsewhere, suggesting that the functional role of gut microbiota in obesity remains unclear and must be investigated $[35,36]$. The microbial components that have been proposed to affect host metabolism include short-chain fatty acids and lipopolysaccharides (LPS) [37]. The high-fat diet (HFD)-induced gut microbiota distribution changes in mice may increase LPS production [38]. In addition, one recent study demonstrated that mice receiving low doses of LPS developed an obese phenotype similar to those fed a HFD [39]. The association between LPS and obesity is less clear, although the low-grade inflammatory effects triggered by LPS are probably involved.

This study investigated whether PTE possesses antiobesity activity and how this activity affects liver gene expression and gut microbiota. We demonstrated that PTE exhibited strong activity, reducing lipid accumulation both in vitro and in vivo. Our experiments also yielded evidence that the anti-obesity effect of PTE treatment is probably caused by the modulation of hepatic gene expression and gut microbiota composition in mice.

\section{Materials and methods}

\section{Materials and reagents}

The roots of PTE were obtained from local Chinese medicine suppliers. Preadipocyte 3T3-L1 cells (BCRC 60159) were obtained from the Bioresource Collection and Research Center (Food Industry Research and Development Institute, Hsinchu, Taiwan). Dexamethasone, 3-isobutyl-1-methylxanthine (IBMS), and insulin were purchased from Sigma-Aldrich (St Louis, MO, USA). Fetal bovine serum (FBS) and Dulbecco's modified Eagle's medium (DMEM) were purchased from Gibco (Waltham, MA, USA).

\section{Preparation of PTE}

Raw PTE was dried and ground into powder (20-40 mesh) using a commercial grinder. Next, $100 \mathrm{~g}$ of the PTE powder was mixed with $1 \mathrm{~L}$ of distilled water and stirred extensively at room temperature. The mixture was subjected to heat reflux extraction at $100^{\circ} \mathrm{C}$ for $1 \mathrm{~h}$. The extraction efficiency (weight of the extract after extraction/weight of the raw materials before extraction) was $\sim 15 \%$. The extract was further concentrated to a final volume of $50 \mathrm{~mL}$ using a rotary evaporator at $70^{\circ} \mathrm{C}$. Lyophilization of the concentrated extract was performed using the following program: -20 to $-10^{\circ} \mathrm{C}$ for $2 \mathrm{~h} ;-10$ to $-5^{\circ} \mathrm{C}$ for $2.5 \mathrm{~h} ;-5$ to $4^{\circ} \mathrm{C}$ for $3 \mathrm{~h} ; 4$ to $12^{\circ} \mathrm{C}$ for $5 \mathrm{~h} ; 12$ to $18^{\circ}$ $\mathrm{C}$ for $5 \mathrm{~h} ; 18$ to $22^{\circ} \mathrm{C}$ for $5 \mathrm{~h}$; and 22 to $28^{\circ} \mathrm{C}$ for $5 \mathrm{~h}$.

\section{Culture and differentiation of 3T3-L1 cells into adipocytes}

3T3-L1 preadipocyte cells were cultured in DMEM containing $10 \% \mathrm{FBS}$ at $37^{\circ} \mathrm{C}$ in $5 \% \mathrm{CO}_{2}$. Cells were maintained 
at $90 \%$ confluency in T75 flasks and subcultured twice per week. Prior to induction of differentiation, 3T3-L1 cells were seeded at a density of $2 \times 10^{4}$ cells/well into a 12 -well culture plate. The cells were then cultured in differentiation medium containing DMEM supplemented with $10 \%$ FBS, $0.5 \mathrm{mM}$ IBMS, $1 \mu \mathrm{M}$ dexamethasone, $10 \mu \mathrm{g} / \mathrm{mL}$ insulin, and $2 \mu \mathrm{M}$ rosiglitazone for $48 \mathrm{~h}$ [40]. The medium was then replaced with DMEM containing 10\% FBS and $10 \mu \mathrm{g} /$ $\mathrm{mL}$ insulin for 4 days. The medium was changed every 2 days until the cells were analyzed.

\section{Cell viability}

Fully differentiated 3T3-L1 cells were seeded at a density of $2 \times 10^{4}$ cells/well in a 96-well culture plate. Viable cells after treatment with different concentrations of PTE for $48 \mathrm{~h}$ were evaluated using MTT colorimetric assay.

\section{Oil Red 0 staining}

Oil Red O staining was performed on fully differentiated 3T3-L1 cells in the presence or absence of PTE for 4 days. The cells were washed twice with PBS, fixed with $3.7 \%$ formaldehyde at room temperature for $20 \mathrm{~min}$, and stained with Oil Red O (Sigma-Aldrich) at $50^{\circ} \mathrm{C}$ for $10 \mathrm{~min}$. Cells were then washed with $60 \%$ isopropanol three times, and $98 \%$ isopropanol was added to dissolve the Oil Red $\mathrm{O}$ dye. The amount of Oil Red O dye was quantitated by absorbance at $492 \mathrm{~nm}$.

\section{Measurement of lipolysis and triglyceride content}

Lipolysis activity of 3T3-L1 cells was determined by measuring the amount of glycerol released into the incubation medium (GY105; Randox, England). The cells were then disrupted by adding $1 \%$ Triton X-100 in PBS and the triglyceride content was measured using a TR212 kit (Randox).

\section{HFD-induced obese mouse model}

All animal experimental procedures followed the protocols approved by the Institutional Animal Care and Use Committee of the Industrial Technology Research Institute (ITRI-IACUC-201473V2) in Hsinchu, Taiwan. Four-week-old male ICR mice were purchased from BioLASCO (Taiwan) and housed in standard laboratory conditions $\left(21-25^{\circ} \mathrm{C}, 40-70 \%\right.$ humidity, and 12 -h light/ dark cycle). All mice were randomly divided into two groups as follows: normal diet (ND; $10 \mathrm{kcal} \%$ fat diet, standard laboratory diet \#1320, Altromin,
Germany) and HFD (60 kcal \% fat diet, Research Diets D12492, Open Source, USA). After 4 weeks on the HFD, obese mice with a weight $10 \%$ higher than that of the ND group mice were selected and divided into two groups: HFD control group, which was given distilled water orally once daily for 5 weeks $(\mathrm{n}=10)$, and PTE treatment group, which was given PTE dissolved in distilled water orally once daily for 5 weeks $(n=10)$.

\section{Measurement of body weight, serum parameters, and epididymal fat content}

The body weight and feed intake of the mice were monitored three times every week. Changes to body weight were calculated as the percentage increase compared with weight before treatment (on Day 0). After 5 weeks of treatment, all mice were fasted for $6 \mathrm{~h}$ and then sacrificed through $\mathrm{CO}_{2}$ overdose. Heart blood was collected and serum was obtained by centrifugation at $6000 \mathrm{rpm}$ at room temperature for $15 \mathrm{~min}$. Alanine aminotransferase (ALT), aspartate aminotransferase (AST), creatinine (CR), triglyceride (TG), total cholesterol (TCHO), and glucose (Glc) were analyzed using a FUJI DRI-CHEM 4000i biochemistry analyzer. Epididymal fat was collected and weighed, and the corresponding data are represented as percentage of body weight. The liver was collected and divided into two parts: one was fixed in the $4 \%$ formalin and the other was frozen in liquid nitrogen and stored at $-80^{\circ} \mathrm{C}$ for RNA extraction.

\section{Histological examination}

Mouse liver tissues were collected, fixed in $4 \%$ formalin for $24 \mathrm{~h}$, and then embedded in paraffin. Tissue sections $5 \mu \mathrm{m}$ in thickness were obtained using a microtome and stained with hematoxylin and eosin. Images of the tissue sections were taken using a light microscope at different magnifications. The severity of liver lesions was determined by a pathologist according to the standard method [41] using the following scores: $1=\operatorname{minimal}(<1 \%)$; $2=$ slight $(1-25 \%) ; 3=$ moderate $(26-50 \%) ; 4=$ moder ate/severe (51-75\%); 5 = severe/high (76-100\%).

\section{RNA extraction and real-time quantitative PCR analysis}

Total RNA was extracted from $100 \mathrm{mg}$ of mouse liver tissue using an RNeasy kit (Qiagen, Germany), and $2 \mu \mathrm{g}$ of RNA was reverse transcribed using a QuantiTect Reverse Transcription Kit (Qiagen). Realtime reverse transcription PCR was performed using the CFX Connect Real-Time PCR System (Bio-Rad, 
Hercules, CA, USA). The final volume of the PCR reaction mixture was $10 \mu \mathrm{L}$ and comprised SYBR green master mix (iQ ${ }^{\mathrm{m}} \mathrm{SYBR}^{\star}$ Green Supermix, BioRad), primer sets for each candidate gene, distilled water, and cDNA. The reaction mixtures were preheated at $95^{\circ} \mathrm{C}$ for $3 \mathrm{~min}$ and then subjected to 40 cycles of melting at $95^{\circ} \mathrm{C}$ for $10 \mathrm{~s}$, annealing/extension at $55^{\circ} \mathrm{C}$ for $10 \mathrm{~s}$, and elongation at $72^{\circ} \mathrm{C}$ for $30 \mathrm{~s}$. All reactions were performed in triplicate and normalized to $\beta$-actin and hypoxanthine guanine phosphoribosyl transferase (HPRT) genes. The data were analyzed using Bio-Rad CFX Manager 3.1 software (Bio-Rad) and are presented as fold changes of the normalized mRNA amounts of the PTE treatment group to those of the HFD control group.

\section{Differential gene expression analysis (RNA-seq quantification)}

Differential gene expression analysis was performed through RNA-seq quantification [42] following the protocol of Illumina performed by Genomics (Taiwan) to obtain $\sim 10$ million reads for each sample. Data analysis first filtered low-quality reads, which was followed by alignment of the sequence of each read against the mouse genome using reference annotation. The gene expression profiles in the PTE treatment and HFD control groups were analyzed and compared. The genes showing differential expression were further categorized through gene ontology (GO) analysis.

\section{Mouse gut microbiota analysis}

Mouse gut microbiota profiles were determined through 16S rRNA gene sequencing of genomic DNA from stool [43]. After 5-week PTE treatment, DNA was extracted from mouse stool samples using a QIAamp DNA Stool Mini Kit (Qiagen, Germany). The Illumina V3 forward 5'-CCTACGGGNGGCWGCAG-3' and V4 reverse 5'-GACTACHVGGGTATCTAATCC-3' PCR primers were used for amplifying bacterial $16 \mathrm{~S}$ rRNA variable regions. The amplicons were then subjected to sequencing (Genomics, Taiwan) and the data analyzed. Briefly, the following steps were performed to obtain the final effective reads: each sample was demultiplexed by dual-index using an in-house written script; pairedend reads were joined using the PEAR program (Exelixis Lab, Heidelberg Institute for Theoretical Studies, German); primer sequences were trimmed from joined reads using the AlienTrimmer program; low-quality end sequences were trimmed off using sliding windows (five nucleotides) with an average quality value $<10$, and short sequences of $<200$ nucleotides were screened out using the Trimmomatic program; and chimeric reads were filtered out using the Mothur v.1.33.3 software package. All effective reads were calculated for pairwise distances between aligned DNA sequences with a cutoff of 0.03 , then clustered into operational taxonomic units (OTU) using the average neighbor algorithm with a cutoff of 0.03 , and finally the OTUs were classified for taxonomic assignment. The bioinformatics software packages Mothur v.1.33.3 and QIIME v1.80 were then used for taxonomic composition of the 16S rRNA sequences using the Greengenes 16S rRNA Taxonomy Database (gg_13_8).

\section{Statistical analysis}

For in vitro assays, data are represented as mean \pm standard deviation (SD). For in vivo assays, data are represented as mean \pm standard error of the mean (SEM). Statistical analysis was performed using Student's $t$-test. Significant differences between groups were determined using one-way ANOVA and Dunnett's multiple comparisons test was used to perform post hoc analysis. In the gut microbiota distribution analysis, the percent distribution of the gut microbiota, richness index (number of observed species), and alpha diversity metrics (Shannon index) of each group were calculated and analyzed using the Pearson's chi-squared test. Differences between the ND group and HFD control group (denoted ${ }^{*}$ ) and between the PTE group and HFD control group $\left(\right.$ denoted $\left.{ }^{*}\right)$ were considered significant at $\mathrm{p}<0.05$ $\left({ }^{\#}\right), \mathrm{p}<0.01\left({ }^{\# \#} /^{* *}\right)$, and $\mathrm{p}<0.001\left(\left(^{\# \# \# / * * *}\right)\right.$.

\section{Results}

\section{Treatment with PTE reduced lipid accumulation in} differentiated 3T3- L1 adipocytes

Differentiated 3T3-L1 adipocytes are a useful model for screening compounds modulating lipid accumulation. As shown in Figure 1(a), lipid accumulation in the adipocytes was $26.9 \%$ of that in the control group after $500 \mu \mathrm{g} / \mathrm{mL}$ PTE treatment was administered for 4 days. Similarly, the TG content in the PTE-treated differentiated adipocytes was $37.8 \%$ that of the control group (Figure 1(b)). The lipolysis activity of the cells, determined by glycerol release, was $24.4 \%$ higher in the PTE treatment group relative to the HFD control group (Figure $1(\mathrm{c})$ ). In addition, no obvious cytotoxicity was detected even after treatment with a relatively high concentration of PTE $(500 \mu \mathrm{g} / \mathrm{mL})$ (Figure 1(d)). These results indicate that treatment of 3T3-L1 cells 

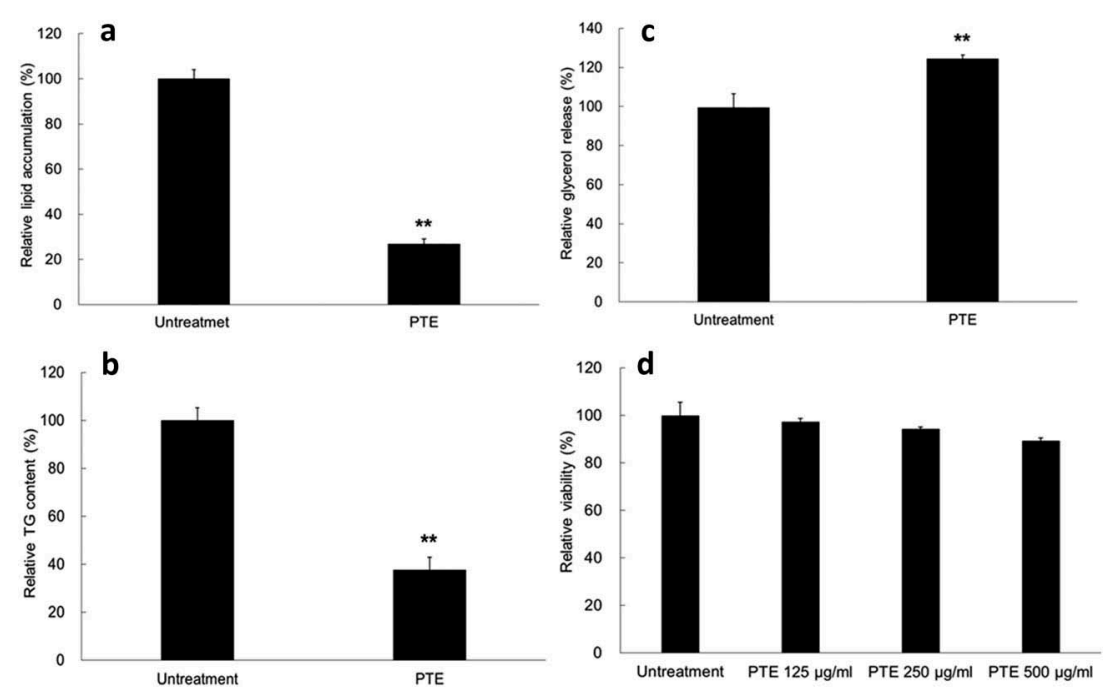

Figure 1. Treatment with PTE inhibited lipid accumulation in 3T3-L1 adipocytes. Undifferentiated 3T3-L1 cells and their differentiated derivatives were used to determine the effect of $500 \mu \mathrm{g} / \mathrm{mL}$ PTE treatment on lipid accumulation (a), intracellular triglyceride content (b), lipase activity (c), and cytotoxicity (d). Percentages were calculated as relative to the adipocyte group without PTE treatment (Untreatment). Data are presented as mean \pm SD. Significant differences from the control group are indicated by ${ }^{*} p<0.05,{ }^{* *} p<0.01$, and ${ }^{* * *} p<0.001$.

with PTE substantially inhibited lipid accumulation in cells without causing cytotoxicity.

\section{PTE inhibited body weight increases and lipid accumulation in HFD-induced obese mice}

To investigate the effects of PTE in vivo, we fed mice a HFD for 4 weeks to induce obesity. Obese mice, which had a body weight that was $10 \%$ higher than the mice fed a ND, were selected and divided into two groups: HFD control, and PTE treatment. Both groups were on the HFD, but mice in the PTE treatment group were given $250 \mathrm{mg} / \mathrm{kg}$ PTE daily for 5 weeks. As demonstrated in Figure 2(a), the body size of the mice treated with PTE was considerably smaller than that of the HFD control mice. The average body weight of mice was $40.4 \pm 0.7 \mathrm{~g}$, $51.9 \pm 1.3 \mathrm{~g}$, and $48.3 \pm 1.5 \mathrm{~g}$ in the ND, HFD control, and PTE treatment groups, respectively (Figure 2(b)). In the 5-week treatment period, the average body weight increases of the ND and HFD controls were $3.7 \pm 0.4 \mathrm{~g}$ and $7.08 \pm 0.6 \mathrm{~g}$, respectively. By contrast, the weight of mice in the PTE group only increased by $3.3 \pm 0.8 \mathrm{~g}$, indicating the effectiveness of PTE in body weight control $(\mathrm{p}<0.01)$ (Figure $2(\mathrm{c})$ ). Figure $2(\mathrm{~d})$ plots the average percentage body weight change in the PTE treatment group mice $(103.4 \% \pm 1.2 \%)$ after 21 days of treatment, which was significantly lower $(\mathrm{p}<0.05)$ than that of the mice in the HFD control group $(106.5 \% \pm$
$0.9 \%)$. At the end of the 5-week treatment, body weight gain in the PTE group was $7.5 \% \pm 1.7 \%$ (Figure 2(e)), significantly lower than that in the ND group $(10.3 \% \pm 1.3 \%)$ and HFD control group $(15.7 \% \pm 1.1 \%)$. Furthermore, the percentage of epididymal fat in the ND group and HFD control group mice was approximately $1.2 \pm 0.2 \%$ and $5.3 \pm 0.2 \%$, respectively, whereas that in the PTE group was significantly lower at $3.7 \pm 0.5 \%$ compared with the HFD control group $(\mathrm{p}<0.01)$ (Figure $2(\mathrm{f})$ ). These results demonstrated that oral administration of PTE $(250 \mathrm{mg} / \mathrm{kg})$ daily for 5 weeks significantly inhibited lipid accumulation in HFD-fed mice. No significant difference in feed intake was observed between mice in the HFD control and PTE treatment groups (Figure $2(\mathrm{~g})$ ), indicating that the anti-obesity effect of PTE was not a result of appetite reduction.

\section{PTE reduced triglyceride levels in the serum of HFD-induced obese mice and exhibited no hepatotoxicity or nephrotoxicity}

In addition to cytotoxicity, this study further evaluated whether administering PTE would produce any adverse effects. Figure 3 illustrates the levels of several major liver and kidney markers in the serum of mice in the PTE treatment group at the end of experiment. The levels of these markers - which included ALT, AST, CR, TCHO, and Glc - in the PTE, HFD control, and ND groups were measured. The elevated TG level in the serum of mice in 
a
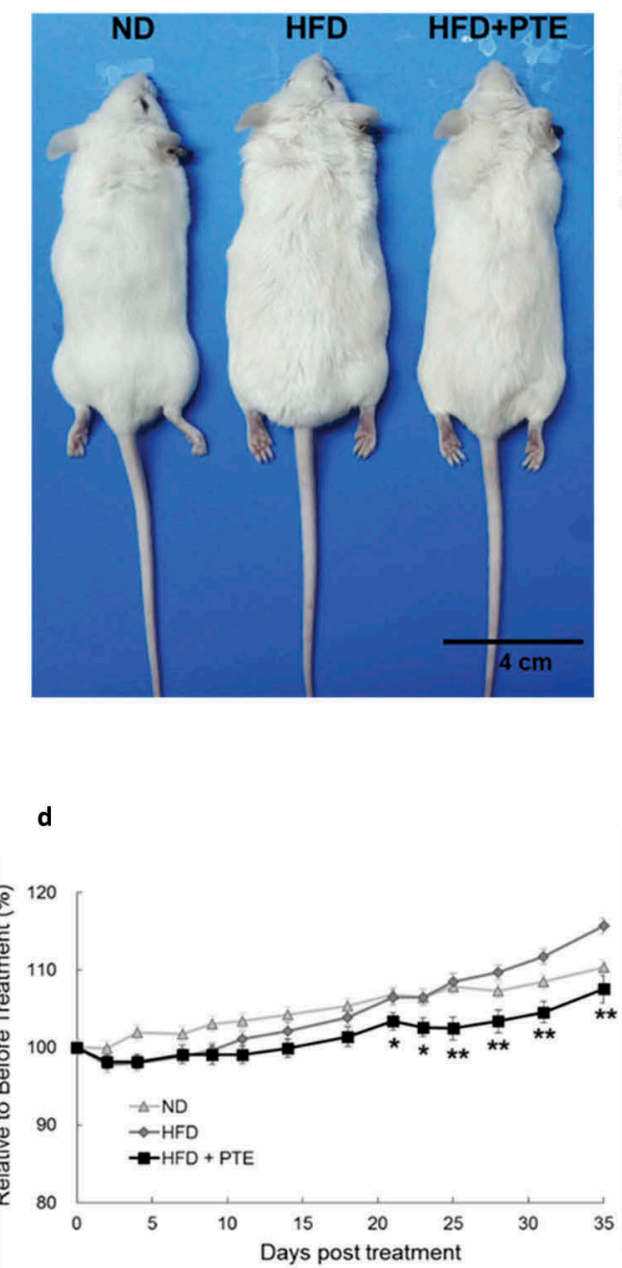

f

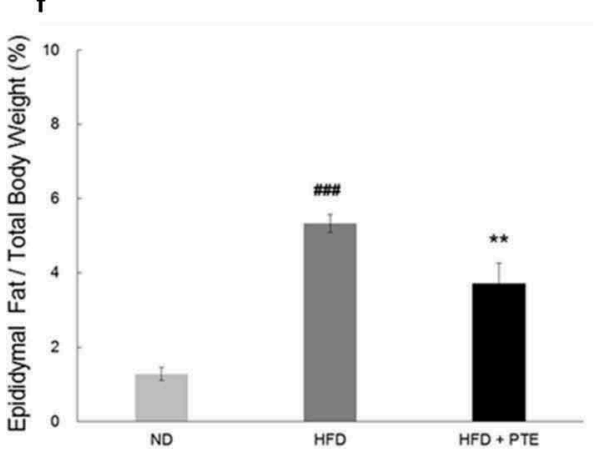

b

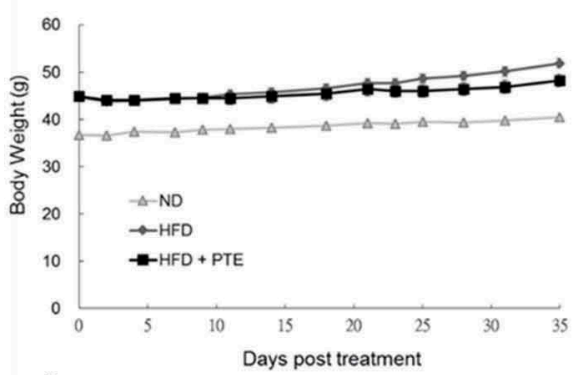

c

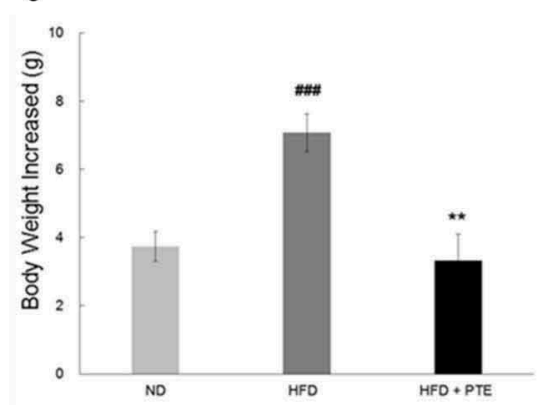

e

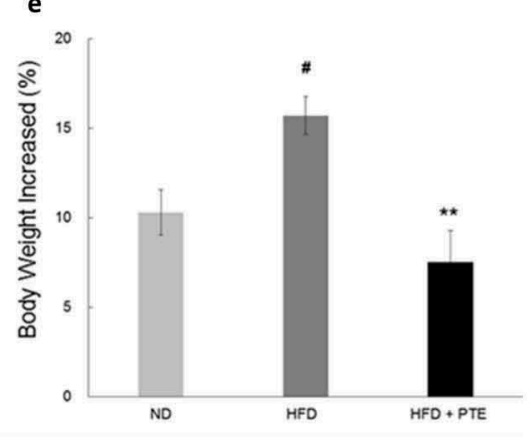

g

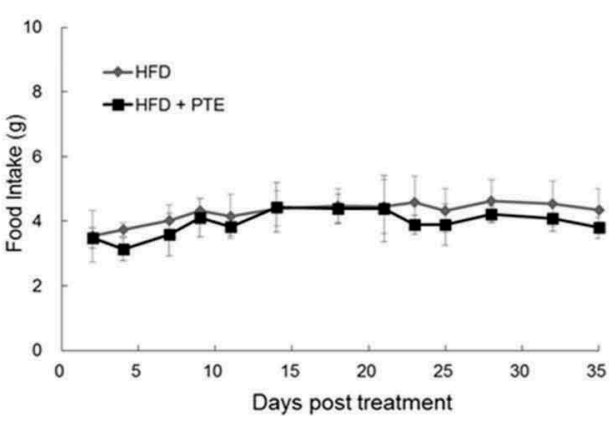

Figure 2. Treatment with PTE inhibited lipid accumulation in HFD-induced obese mice without altering food intake. Obese mice derived from HFD feeding for 4 weeks were divided into the HFD control group $(n=10)$ and PTE treatment group ( $n=10)$. Mice in the HFD control group received distilled water, whereas mice in the PTE group were administered $250 \mathrm{mg} / \mathrm{kg}$ PTE orally daily for 5 weeks. The normal diet group (ND, $\mathrm{n}=8$ ) were fed a ND throughout the entire experiment period. (a) Phenotypes of mice in ND, HFD control, and PTE treatment groups. Scale bar $=4 \mathrm{~cm}$. (b) Body weight (g) plot of each experimental group during the treatment period. (c) Average increased body weight (g) of each experimental group. (d) Body weight (\%) plot at each measurement day relative to the first day of treatment during the experimental period. (e) Mean relative increased body weight (\%) of each group after treatment for 5 weeks. (f) Weight of epididymal fat of mice in each experimental group after treatment for 5 weeks. (g) Amounts of food intake in the HFD control and PTE treatment groups. Data are presented as mean \pm SEM. Significant differences between the ND group and HFD control group are indicated by ${ }^{\#}<0.05$, ${ }^{\# \#}<0.01$, and ${ }^{\# \# \#} p<0.001$. Significant differences between the PTE group and HFD control group are indicated by ${ }^{*} p<0.05$, ${ }^{* *} p<0.01$, and ${ }^{* *} p<0.001$. 

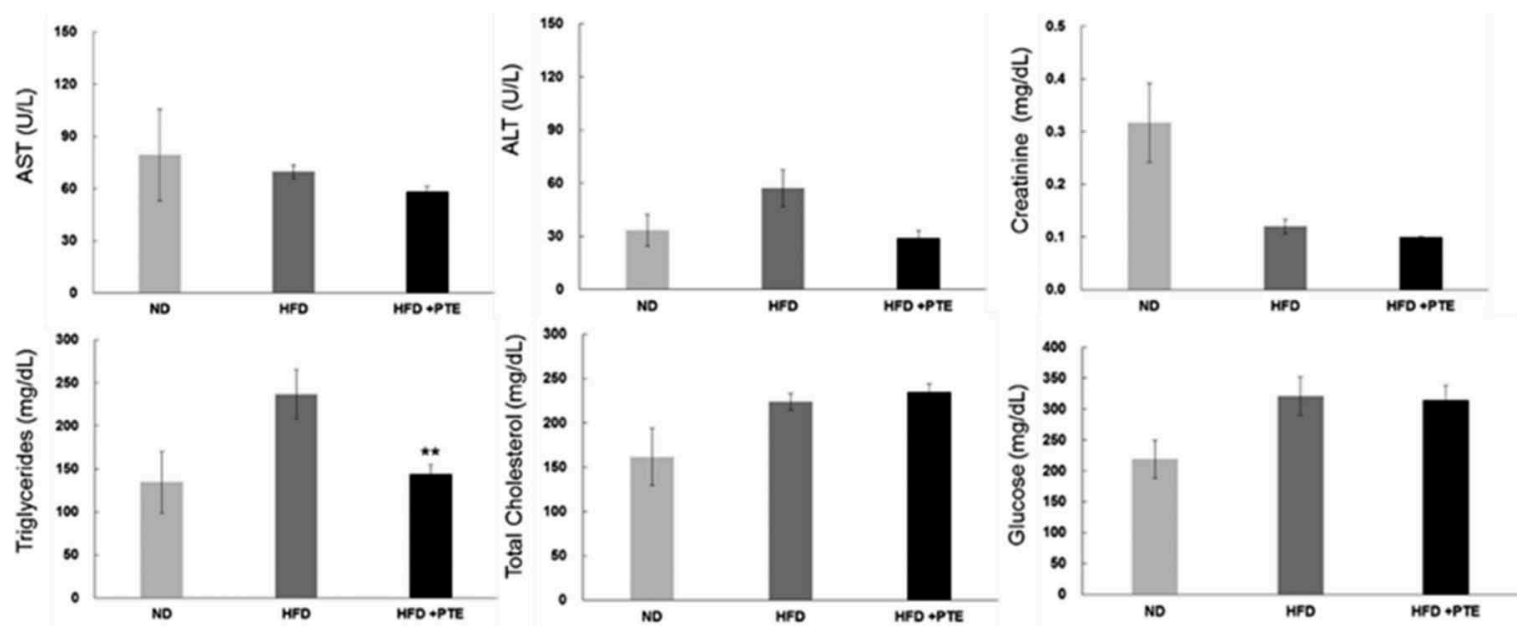

Figure 3. Treatment with PTE reduced serum triglyceride levels without producing hepatotoxicity or nephrotoxicity. Serum was collected from each experimental group and the following parameters were determined: alanine aminotransferase (ALT), aspartate aminotransferase (AST), nephrotoxicity indicator (creatinine), triglycerides, total cholesterol, and glucose. Data are presented as the mean \pm SEM. Significant differences between the PTE treatment group and HFD control group are indicated by ${ }^{*} p<0.05$, ${ }^{* *} \mathrm{p}<0.01$, and ${ }^{* * *} \mathrm{p}<0.001$.

the HFD group $(236.9 \pm 28.6 \mathrm{mg} / \mathrm{dL})$ decreased significantly $(144.0 \pm 11.0 \mathrm{mg} / \mathrm{dL})$ after PTE treatment $(\mathrm{p}<0.01)$. This finding is consistent with the hypothesis that PTE inhibited lipid accumulation.

\section{Treatment with PTE attenuated liver steatosis in HFD-induced obese mice}

The histology of mouse liver tissues in each of the experimental groups was examined after the 5 -week treatment (Figure 4(a)). As demonstrated in Figure 4(b), HFD feeding for 5 weeks resulted in multifocal and moderate microvesicular fatty changes in the liver of the HFD control group. The average liver lesion score of the HFD group was $2.3 \pm 0.3$, significantly higher than that of the ND group $(\mathrm{p}<0.001)$. However, after 5 weeks of PTE treatment, the microvesicular fatty change observed was reduced and the liver lesion score had decreased to $0.3 \pm 0.2$, which was significantly $(\mathrm{p}<0.001)$ lower than that of the HFD group. This histopathological finding strongly suggests that PTE has a protective effect on HFD-induced chronic liver injuries.

\section{Effect of PTE treatment on liver gene expression in HFD-induced obese mice}

To investigate the effects of PTE treatment on liver gene expression, an RNA-seq study was performed using RNA samples pooled from three independent mouse livers from each experimental group. We excluded genes with a transcript read number less than 15 and selected those with fold changes $\geq 1$.5fold between the experimental groups. Additional files (Table S1A and S1B) compile the 55 upregulated and 72 downregulated genes in the PTE group, and the top 30 up- and downregulated genes are listed in Tables 1 and 2 , respectively. These genes were further categorized using GO analysis with an emphasis on those related to lipid metabolism and catabolism, as shown in Table 3.

A large proportion of the top PTE downregulated genes were related to lipid and cholesterol biosynthesis. PTE downregulated genes include serpin family member 12 (Serpina12), mevalonate diphosphate decarboxylase (Mvd), proprotein convertase subtilisin/kexin 9 (Pcsk9), squalene monooxygenase (Sqle), farnesyl diphosphate synthase (Fdps), isopentenyl-diphosphate delta isomerase 1 (Idi1), and cytochrome P450 family 51 (Cyp51) (Table 1). Similarly, PTE treatment activated the expression of several genes that facilitate lipid or cholesterol transfer and lipid oxidation, such as phosphatidylcholine transfer protein (Pctp), ATP-binding cassette subfamily $G$ member 5 (Abcg5), cytochrome P450 family 2a (Cyp2a5, Cyp2a22, and Cyp2a12), phosphatidic acid phosphohydrolase (Lpin1), and fatty acid-binding protein 5 (Fabp5) (Table 2). Compellingly, the expression of two inflammation-related genes, interleukin-1-beta (IL-1 $\beta$ ) and serum amyloid A1 (Saa1), was downregulated 0.29- and 0.47fold (Table 1), respectively, by PTE treatment, suggesting that PTE exhibits anti-inflammatory activity.

To identify the key regulator responsible for PTE treatment, we investigated the gene expression of the major transcription factors (Table 4) that regulate lipid biosynthesis, metabolism, and oxidation. The most notable change in the expression level of transcription factors regulating lipolysis was that in PPARa. PPARa 


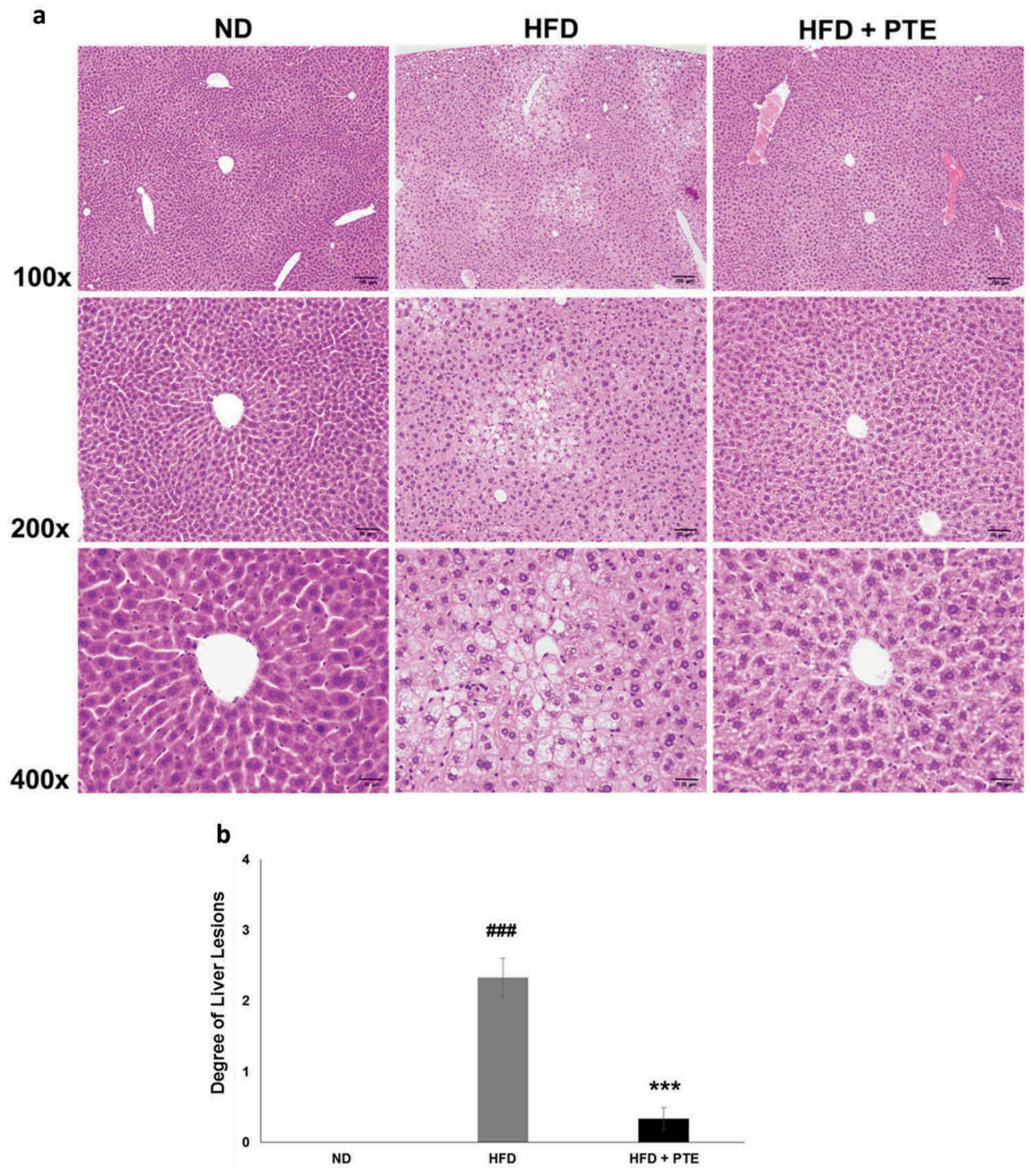

Figure 4. Treatment with PTE attenuated HFD-induced liver lesion. Comparison of histopathological alterations of the liver in the ND, HFD control, and PTE groups. (a) Tissue sections were prepared and stained with hematoxylin and eosin. The sections were photographed at 100x, 200x, and 400x magnifications. Scale bars $=100,50$, and $20 \mu \mathrm{m}$ at each magnification, respectively. (b)

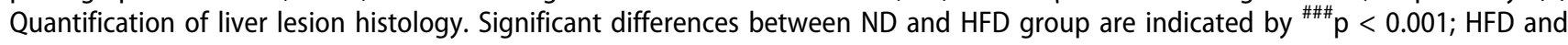
PTE group are indicated by ${ }^{* *} p<0.001$.

expression was upregulated 2.28-fold when the HFDinduced obese mice were administered PTE for 5 weeks. The expression of three transcription factors, Cebpa, Srebfl, and PPAR $\gamma$, has been reported previously to be inhibited by PTE-containing herb mixtures SH21B and KBH-1 [25,27]. However, the expression levels of these transcription factors in mouse liver were not altered significantly after treatment with PTE.

To verify the differentially expressed genes identified by RNA-seq, real-time quantitative PCR analysis was performed and analyzed. As demonstrated in Figure 5 (a), elevated expression of Abcg5 (1.89-fold), Lpin1 (1.51-fold), Pctp (4.32-fold), and PPARa (3.46-fold) were observed using real-time PCR. Most of the PTE downregulated genes - including IL-1 $\beta$ (0.47-fold), Idi1 (0.45-fold), Fdps (0.41-fold), Sqle (0.28-fold), Cyp51 (0.55-fold), Mvd (0.47-fold), and PPARy (0.72fold) - displayed a similar trend as determined using real-time PCR. No significant changes between the HFD control and PTE treatment groups were noted using either RNA-seq or real-time PCR analysis for the expression of several genes that have been related to lipid accumulation in previous studies [25,44], including acetyl-CoA carboxylase 1 (Acaca), ATP-citrate lyase (Acly), fatty acid synthase (Fasn), low-density lipoprotein receptor (Ldlr), peroxisomal acyl-coenzyme A oxidase 1 (Acox1), and forkhead box O1 (Foxo1). 
Table 1. Top 30 downregulated genes upon PTE treatment.

\begin{tabular}{|c|c|}
\hline Gene & Fold change ${ }^{a}$ \\
\hline Rpl14-ps1 & 0.05 \\
\hline Marco & 0.07 \\
\hline BC021614 & 0.12 \\
\hline Creld2 & 0.23 \\
\hline Mup19 & 0.24 \\
\hline 2310057J18Rik & 0.26 \\
\hline Myom3 & 0.26 \\
\hline Mvd & 0.28 \\
\hline$\| 1 \beta$ & 0.30 \\
\hline Sqle & 0.31 \\
\hline Pira1 & 0.31 \\
\hline Fam $25 c$ & 0.31 \\
\hline Lcn2 & 0.32 \\
\hline Сyp2d12 & 0.35 \\
\hline Slc17a9 & 0.35 \\
\hline Gale & 0.36 \\
\hline $\lg 5 f 23$ & 0.37 \\
\hline Serpina3g & 0.38 \\
\hline XIr3a & 0.39 \\
\hline Rsc1a1 & 0.40 \\
\hline $\lg s f 6$ & 0.40 \\
\hline Acnat2 & 0.41 \\
\hline Syvn1 & 0.41 \\
\hline Rhbg & 0.42 \\
\hline Eif3j2 & 0.42 \\
\hline Saa2 & 0.42 \\
\hline Lad1 & 0.42 \\
\hline Hyou1 & 0.42 \\
\hline Pqlc1 & 0.43 \\
\hline Manf & 0.43 \\
\hline
\end{tabular}

Table 2. Top 30 upregulated genes upon PTE treatment.

\begin{tabular}{lc}
\hline Gene & Fold $^{\text {change }}{ }^{\mathrm{a}}$ \\
\hline Cd34 & 4.88 \\
Pctp & 4.77 \\
Cela1 & 4.44 \\
Cyp2a5 & 4.16 \\
Hspa1a & 3.57 \\
Tff3 & 3.43 \\
Rassf4 & 3.42 \\
Lpin1 & 3.29 \\
Fam171b & 3.26 \\
Afap111 & 3.14 \\
Rgs16 & 2.99 \\
Cyp2a22 & 2.92 \\
Vsig10 & 2.85 \\
Cyp39a1 & 2.83 \\
Hspa1b & 2.82 \\
Cfap53 & 2.76 \\
Grem2 & 2.76 \\
Akr1e1 & 2.64 \\
Ahcy & 2.43 \\
Lyve1 & 2.36 \\
Alas1 & 2.33 \\
PPARa & 2.28 \\
Cyp2a12 & 2.26 \\
Plxna2 & 2.23 \\
Rsph3b & 2.20 \\
Ceacam2 & 2.14 \\
Smad9 & 2.13 \\
Gm10052 & 2.12 \\
Dsg1c & 2.10 \\
Slco1a4 & 2.10 \\
\hline a Fol changeprents & \\
\hline
\end{tabular}

${ }^{\mathrm{a}}$ Fold change represents the ratio of PTE group to HFD group.
Figure 5(b) shows the genes whose expression was altered by PTE treatment according to both the realtime quantitative PCR and RNA-seq results. These differentially expressed genes are promising targets for development of future anti-obesity treatments.

\section{Effect of PTE on gut microbiota composition in HFD-induced obese mice}

To investigate whether the gut microbiota profile was altered in the mice that received PTE treatment, we collected the stool of the ND group $(n=8)$, HFD control group $(n=10)$, and PTE treatment group $(n=10)$ after a 5week treatment course. Genomic DNA was extracted from the stools, and the distribution profiles of different bacterial groups were determined based on $16 \mathrm{~S}$ rRNA sequences. Figure 6(a) shows the results of principal component analysis, which demonstrate obvious differences in gut microbiota profile between the ND and HFD control groups. Notably, significant differences in gut microbiota profiles between the ND, HFD control, and PTE treatment groups were observed. The richness index (number of observed species) and alpha diversity metrics (Shannon index) of the gut microbiota in each group were also calculated (Figure S1). The findings indicate that the differences in gut microbiota between the ND, HFD control, and PTE treatment groups were highly significant $(\mathrm{p}<0.001)$. Figure 6(b) displays the dominant microbiota population in the ND, HFD control, and PTE treatment groups at the phylum level. As expected, the alteration of gut microbiota composition by HFD feeding is significant ( $p<0.0001$ ). When mice fed a HFD were administered PTE for 5 weeks, the gut microbiota population was also significantly different from that of the HFD control $(p<0.05)$. Comparison of microbiota profiles in the ND and HFD control groups revealed that the Firmicutes population was increased in the HFD group, whereas the Bacteroidetes population was decreased, resulting in a reduction of the $\mathrm{B} / \mathrm{F}$ ratio from $235.93 \%$ in the ND group to $34.62 \%$ in the HFD control group (Figure 6(c)). This result is consistent with several previous findings that Firmicutes are dominant in obese individuals $[37,45]$. Additionally, the lower $\mathrm{B} / \mathrm{F}$ ratio in the HFD-fed mice was found to be mitigated to $62.73 \%$ by 5 weeks of PTE treatment. Moreover, the Proteobacteria population, which accounted for only $0.1 \%$ of the microbial population in the HFD control group, was $2 \%$ in the PTE treatment group. However, another dominant population, Deferribacteres, was $1.1 \%$ in the HFD control group, which was decreased to $0.2 \%$ by PTE treatment, a level similar to that of the ND group.

At the class level (Figure 6(d)), the differences in gut microbiota distribution between the ND group and HFD control and between the HFD control and PTE treatment 
Table 3. Gene ontology (GO) analysis of the differential expression genes.

\begin{tabular}{|c|c|}
\hline GO ID/Function & Genes \\
\hline 0006629/Lipid metabolic process & $\begin{array}{l}\text { Pcsk9/Fdps/Elovl3/Cyp2a12/Cyp2a5/Cyp51/Lpin1/G6pc/ll1b/Fabp5/Pctp/Mvd/Saa1/Sqle/Acnat2/ } \\
\text { Cyp2a22/Hsd17b6/Slco1a4/Idi1/Cyp2d12/Cyp39a1/Msmo1/Serpina12/Gpcpd1 }\end{array}$ \\
\hline 0044255/Cellular lipid metabolic process & $\begin{array}{l}\text { Pcsk9/Fdps/Elov13/Cyp2a12/Cyp2a5/Lpin1/G6pc/Fabp5/Mvd/Acnat2/Cyp2a22/Idi1/Cyp2d12/ } \\
\text { Msmo1/Serpina12/Gpcpd1 }\end{array}$ \\
\hline 0008610/Lipid biosynthetic process & Fdps/Elovl3/Cyp51/Lpin1/ll1b/Fabp5/Mvd//di1/Cyp39a1/Msmo1/Serpina12 \\
\hline 0016042/Lipid catabolic process & Lpin1/IIb/Сyp39a1/Gpcpd1 \\
\hline 0044241/Lipid digestion & Abcg5 \\
\hline 0006631/Fatty acid metabolic process & Elovl3/Cyp2a12/Cyp2a5/Lpin1/Acnat2/Cyp2a22/Cyp2d12/Msmo1 \\
\hline 0022600/Digestive system process & Abcg5/Rsc1a1 \\
\hline $1,901,568 /$ Fatty acid derivative metabolic process & Сyp2a12/Сyp2a5/Сyp2a22/Сyp2d12 \\
\hline 0050892/Intestinal absorption & Abcg5/Rsc1a1 \\
\hline 0033559/Unsaturated fatty acid metabolic process & Сур2a12/Сур2a5/Сyp2a22/Сyp2d12 \\
\hline
\end{tabular}

Lipid metabolism-related genes with 1.5-fold up- or downregulation upon PTE treatment are listed.

Table 4. Expression levels of gene encoding transcription factors involved in adipogenesis.

\begin{tabular}{llc}
\hline Full name & Gene & Fold $^{\text {change }}{ }^{\mathrm{a}}$ \\
\hline Insulin-induced gene 1 & Insig1 & 0.80 \\
Nuclear receptor subfamily 1, group H, member 3 & Nr1h3 & 0.92 \\
Hypoxia inducible factor 1, alpha subunit & Hif1a & 0.93 \\
CCAAT/enhancer binding protein (C/EBP) alpha & Cebpa & 1.03 \\
Peroxisome proliferator activated receptor gamma & Ppary & 1.03 \\
Peroxisome proliferator activated receptor alpha & Ppara & 2.28 \\
Catenin beta 1 & Ctnnb1 & 1.05 \\
Upstream transcription factor 1 & Usf1 & 1.07 \\
Retinoblastoma 1 & Rb1 & 1.17 \\
Endothelial PAS domain protein 1 & Epas1 & 1.18 \\
Nuclear receptor interacting protein 1 & Nrip1 & 1.23 \\
Forkhead box O1 & Foxo1 & 1.27 \\
Kruppel-like factor 15 & Klf15 & 1.34 \\
Sterol regulatory element binding protein 1 & Srebf1 & 1.37 \\
Kruppel-like factor 6 & Klf6 & 1.42 \\
High mobility group AT-hook 1 & Hmga1 & 1.52 \\
\hline
\end{tabular}

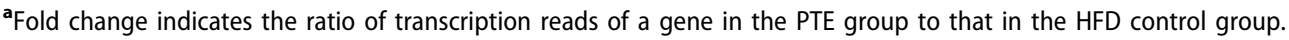

group were both highly significant $(\mathrm{p}<0.001)$. The most abundant bacterial population in the mouse gut at the class level was Bacteroidia. In this study, the Bacteroidia population accounted for $69.4 \%$ in the ND group, $25 \%$ in the HFD control group, and $37.1 \%$ in the PTE group. The Deferribacteres family, only $0.1 \%$ population in the ND group, was enriched in the HFD control group (1.1\%) but decreased to $0.2 \%$ in the PTE group. Similarly, the Clostridia population was higher in the HFD control group (72.3\%) but lower (58.9\%) in the PTE group. Deltaproteobacteria, a reportedly abundant population in the gut, was present in relatively low levels in the HFD control group (0.1\%), but substantially higher at $1.6 \%$ in the PTE treatment group. Treatment with PTE also increased the populations of Bacteroidaceae, Rikenellaceae, S24-7, Desulfovibrionaceae, and Enterobacteriaceae and decreased those of Lachnospiraceae, Ruminococcaceae, and Peptococcaceae (Figure 6(e)) compared with the HFD group. These results suggest that HFD feeding could dysregulate gut microbiota distribution in mice and that treatment with PTE could partially restore the microbiota distribution to one more similar to that of the ND group.

\section{Discussion}

PTE is a commonly used herbal medicine in Chinese society. Treating fully differentiated 3T3L1 adipocytes with PTE decreased lipid accumulation in the cells by reducing lipid formation and TG content and enhancing lipase activity, which is encouraging. The inhibitory effect of PTE on lipid accumulation was also observed in HFDinduced obese mice and resulted in a smaller body size, reduced TG levels, lower body weight, and less epididymal fat after treatment with $250 \mathrm{mg} / \mathrm{kg}$ PTE for 5 weeks. The weight-gain inhibition rate, which is defined as [1(body weight gained in PTE treated mice)/(body weight gained in HFD control mice) $\times 100 \%$ ], was $50.06 \%$ after 5 weeks of PTE treatment. This finding indicates that PTE is relatively potent than the clinically used drug orlistat (30.88\%) in weight controling. [11]. Although PTE seems to be less effective than metformin $(69.03 \%)$ [46], another clinically used anti-obesity drug, the duration of metformin treatment was 12 weeks, much longer than that of the PTE treatment (5 weeks) in this study. In addition, histological examination demonstrated that fat accumulation in the liver was attenuated by PTE treatment. All these findings strongly suggest that PTE contains anti- 
a
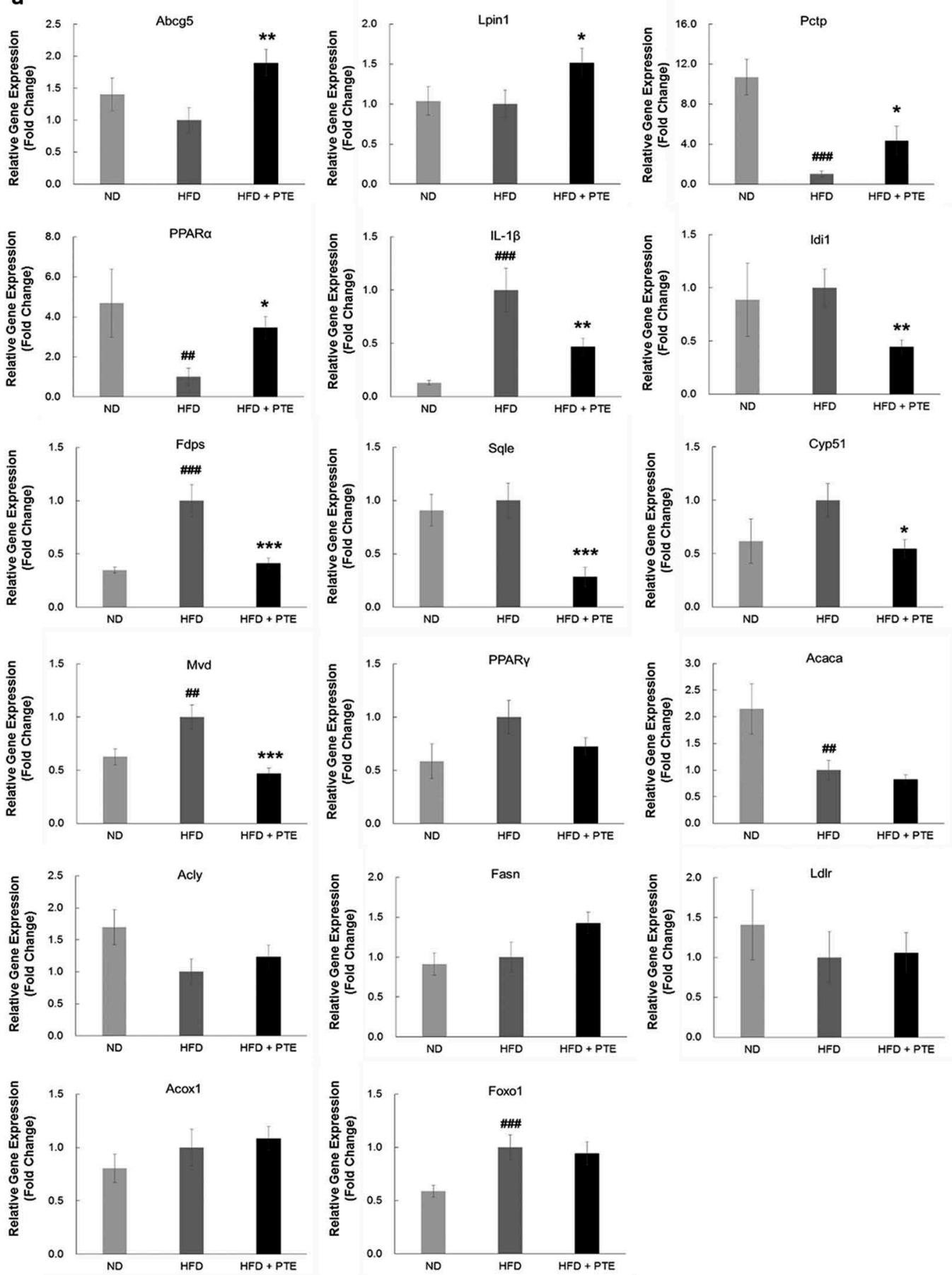

Figure 5. Confirmation of PTE-induced differentially expressed genes using real-time PCR. (a) The genes showing differential expression in the RNA-seq study were verified using real-time quantitative PCR. Expression of each gene was normalized to that of $\beta$-actin and hypoxanthine guanine phosphoribosyl transferase (HPRT) genes. (b) Dot plot displaying the relative degrees of differential expression of selected genes. Fold changes indicate the gene expression in the PTE treatment group relative to that in the HFD control group. Data are presented as the mean \pm SEM. Significant differences between the ND group and HFD control group are indicated by ${ }^{\#} p<0.05,{ }^{\#} p<0.01$, and ${ }^{\# \# \# ~}<0.001$. Significant differences between the PTE group and HFD control group are indicated by ${ }^{*} p<0.05,{ }^{* *} p<0.01$, and ${ }^{* *} p<0.001$. 


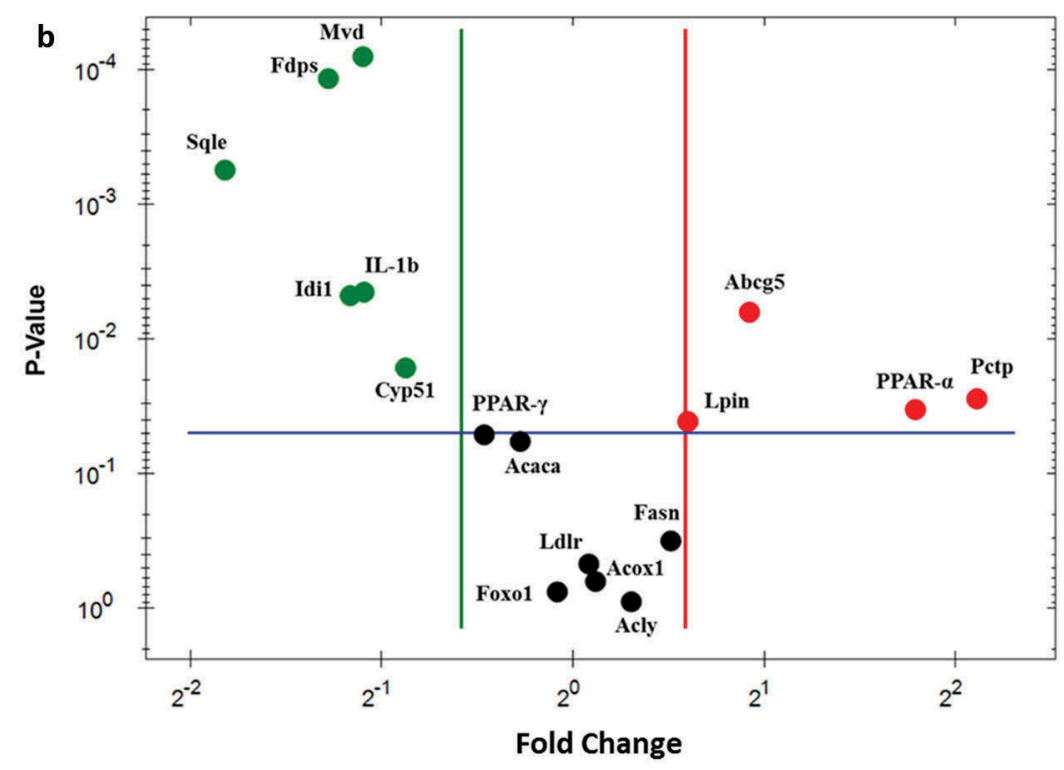

Figure 5. Continued.

adipogenic compounds that warrant further investigation. Isolated phenylpropanoid-type metabolite tenuifoliside A [21] and triterpenoid saponin [22] from PTE were previously demonstrated to possess anti-inflammatory and antidepressant activities, respectively. Whether these compounds inhibit lipid accumulation remains unclear. Therefore, identification and purification of the active ingredients in PTE that inhibit lipid accumulation must still be performed.

Low toxicity is one of the key factors determining whether a compound can be developed into a drug. Even when 3T3-L1 cells were treated with a high concentration $(500 \mu \mathrm{g} / \mathrm{mL})$ of PTE, they did not exhibit obvious cytotoxicity. The levels of serum inflammatory markers, such as ALT, AST, and CR, were not elevated after mice were treated with PTE for 5 weeks. Furthermore, mice administered PTE remained active and had a similar feed intake as the control group. Together, these findings suggest that PTE is safe and could be a possible candidate with which to treat obesity. However, additional toxicology studies and clinical trials are required before PTE can be developed into a food supplement to moderate lipid accumulation.

The verification of genes differentially expressed in PTE-treated mice will help to explain how the plant extract inhibits lipid accumulation. Notably, one important transcription factor, PPARa, was activated after PTE treatment. PPARa is a ligand-activated transcription factor involved in fatty acid metabolism [47]. Earlier evidence indicated that $\mathrm{PPARa}^{-/-}$mice had severe hepatic steatosis [48]. In particular, several genes upregulated by PTE, such as Lpin-1, Pctp, and Abcg5, were direct target genes of PPARa [49]. Lpin-1 encodes a phosphatidate phosphatase that prevents the accumulation of lipid intermediates in cells [50]. Pctp is a highly specific phospholipid lipid transfer protein. Studies concerning Pctp $^{-/-}$mice have found that body fat composition was increased in $\mathrm{Pctp}^{-/-}$ mice [49,51]. The function of Abcg5 is to maintain sterol balance in vertebrates [52]. More studies are required to clarify the compounds in PTE that may activate Lpin-1, Pctp, and Abcg5 gene expression through directly interaction with PPARa.

Several genes associated with obesity and anti-obesity treatment are downregulated by PTE, as has been reported in previous research. Mvd, a lipogenic enzyme, was downregulated in ob/ob mice receiving fatostatin treatment [53]. The expression of Pcsk9, associated with hypercholesterolemia, decreased after berberine treatment of HFDinduced obese mice [54]. The gene Serpina12 was found to be downregulated by Peucedanum japonicum extract in HFD-induced obese mice [55]. These results suggest that PTE inhibits lipid accumulation not only by lipid transfer and oxidation mediated by PPARa regulation, but also by inhibition of genes participating in lipogenesis and cholesterol biosynthesis. Although we have discovered differential gene expression in the livers of HFD-induced obese mice after PTE treatment, the effects of PTE on adipose tissue remain unclear. The complete mechanism of lipid accumulation inhibition of PTE will need to be further investigated.

Obesity has been recognized as an outcome of chronic low-grade inflammation. In the liver of HFD-induced obese mice, lipid accumulation activates Kupffer cells to release a large amounts of proinflammatory cytokines, such as TNFa, IL-1 $\beta$, and IL-6 [56,57]. The effects of cytokines could be attenuated with clodronate to deplete Kupffer cells, resulting in a reduction of IL-1 $\beta$, TG, and 
a
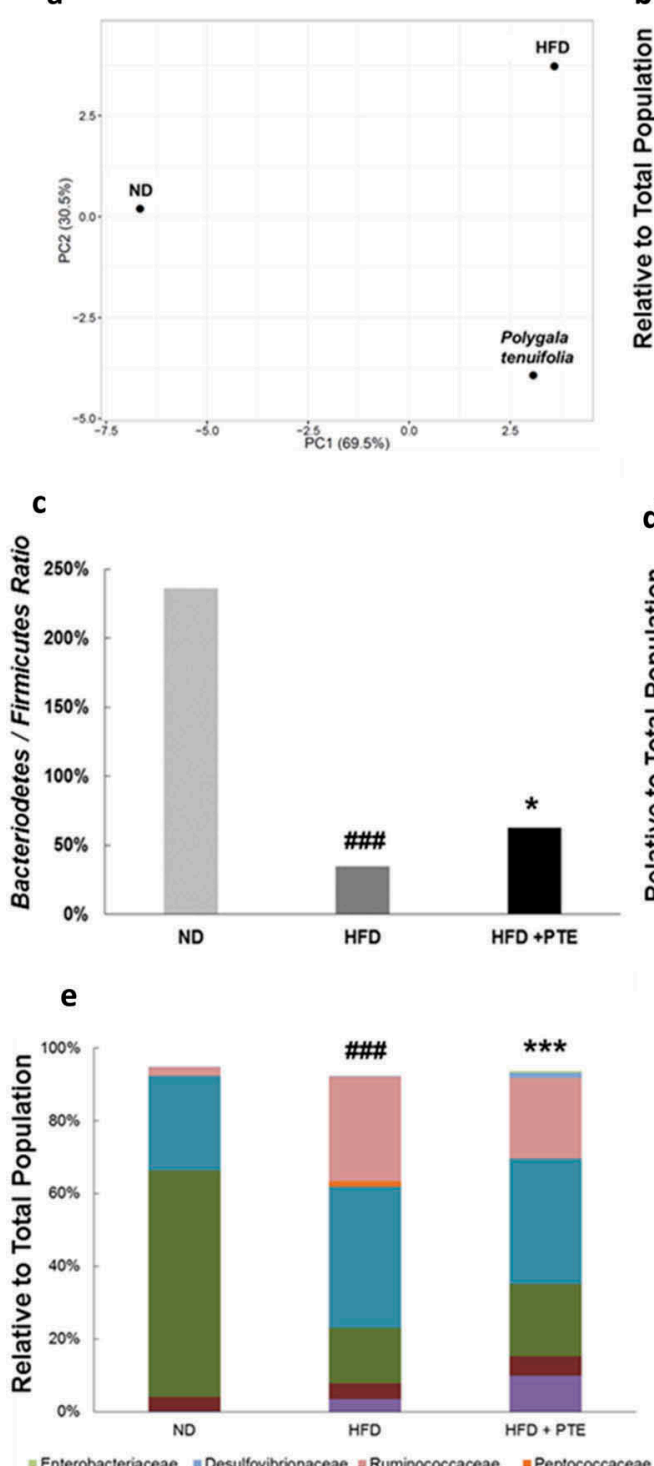
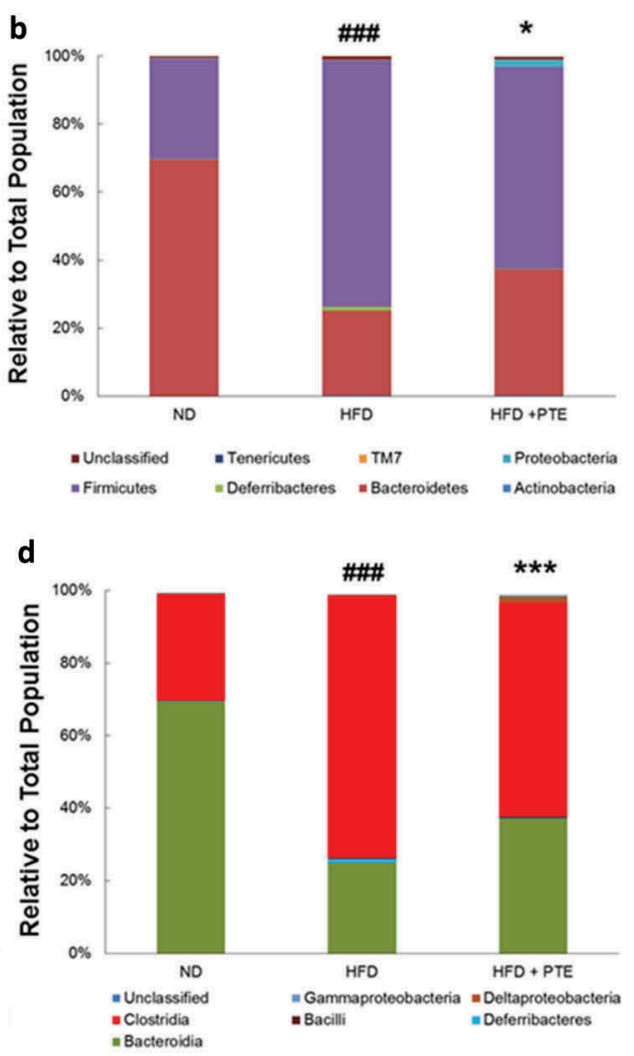

Figure 6. Gut microbiota profiles in HFD control and PTE-treated mice. (a) Diversity of gut microbiota in ND, HFD control, and PTE treatment groups was determined using principal component analysis. The dominant bacterial population in each group at the phylum level (b), class level (d), and family level (e) are shown. (c) Bacteroidetes to Firmicutes ratio of ND, HFD control, and PTEtreated mice. Significant differences between the ND group and HFD control are indicated by ${ }^{\#} p<0.05$, \# $p<0.01$, and ${ }^{\# \# \#} p<0.001$. Significant differences between the PTE group and HFD control are indicated by ${ }^{*} p<0.05$, ${ }^{* *} p<0.01$, and ${ }^{* * *} \mathrm{p}<0.001$.

lipogenic enzyme expression levels. Conversely, treating primary mouse hepatocytes with IL- $1 \beta$ substantially increased TG content and fatty acid synthase expression [58]. Our study demonstrated that IL- $1 \beta$ expression was significantly inhibited by PTE treatment, which echoes a paper reporting that PTE decreased the production of TNF $\alpha$ and IL-1 $\beta$ [21]. Therefore, we hypothesize that PTE acts through a mechanism similar to anti-proinflammatory cytokine therapy, which was successful in improving glucose tolerance and insulin resistance in obese mice [59].
Strong evidence has been provided recently indicating that gut microbiota is an important factor affecting the development of obesity [60,61]. Gut microbiota distribution varied after prolonged HFD feeding in rats [32]. Changes in gut microbiota profiles may increase LPS release and thus cause chronic inflammation in obese patients [62]. These findings support the mechanism that obesity development is highly correlated with low-grade chronic inflammation and gut microbiota alteration. A HFD was shown to increase the Firmicutes population, which strengthens lipid droplet 
formation and absorption [63]. Additionally, a HFD causes a decrease in the Bacteroidetes population. This study elucidated that the reduced $\mathrm{B} / \mathrm{F}$ ratio caused by a HFD could be partly restored by PTE treatment. In addition, 5-week PTE treatment decreased the population of Deferribacteres and increased that of Proteobacteria. These changes in gut microbiota profiles were similar to the evidence presented in previous reports for treating obesity with prebiotics (oligofructose) and antibiotics (vancomycin or penicillin) [64,65]. Furthermore, PTE treatment caused a reduction in both Lachnospiraceae and Ruminococcaceae populations, which positively correlate with obesity, in subjects fed a HFD [66,67]. In addition, PTE treatment restored the HFD-mediated reduction in the S24-7 population (a Bacteroidetes phylum), an effect also observed when subjects' physical activity levels are increased [68].

\section{Conclusion}

This study reports that PTE is an inhibitor of lipid accumulation in HFD-induced obese mice. After 5 weeks of treatment with PTE, increased body weight, elevated serum TG content, and liver steatosis were all reduced. Transcriptomic analysis revealed that genes involved in lipid and cholesterol biosynthesis and metabolism were altered after PTE treatment. The expression of the master transcription factor that regulates lipid oxidation (PPAR $\alpha$ ) was significantly higher relative to the HFD control mice. Furthermore, the low-grade chronic inflammation of the obesity caused by the HFD was also attenuated after PTE treatment, as demonstrated by the reduction of IL-1 $\beta$ expression level. In addition, treatment with PTE also restored the reduced $\mathrm{B} / \mathrm{F}$ ratio caused by the HFD, enriched the Proteobacteria population, and reduced the Deferribacteres population. These shifts in particular gut microbiota populations are similar to those resulting from treatment of obese mice with prebiotics or antibiotics. These results suggest that PTE could be developed into a supplement to reduce lipid accumulation through attenuation of low-grade chronic inflammation and alteration of gut microbiota in obesity.

\section{Acknowledgements}

The authors thank Professor Jiunn-Wang Liao at the Institute of Veterinary Pathobiology, National Chung-Hsing University, Taiwan, for his assistance in the pathological analysis of liver lesions. This work was financially supported by the Industrial Technology Research Institute, Hsinchu, Taiwan.

\section{Availability of data and materials}

All data generated or analyzed during this study are included in this published article and its supplemental information files.

\section{Authors' contributions}

RJG, CYL, and CTH participated in the in vitro work; YYC and $\mathrm{CHC}$ were responsible for plant extraction; YJH executed in vivo experiments; Chun-Chung Wang designed the experiments and performed in vivo work, data analysis, and manuscript writing; $\mathrm{CHC}$ and $\mathrm{HYC}$ were advisors.

\section{Disclosure statement}

No potential conflict of interest was reported by the authors.

\section{Ethics approval and consent to participate}

All animal experimental procedures followed the protocols approved by the Institutional Animal Care and Use Committee of the Industrial Technology Research Institute (ITRI-IACUC-2014-73V2) in Hsinchu, Taiwan.

\section{Funding}

This work was supported by the Industrial Technology Research Institute, Taiwan.

\section{References}

[1] WHO. Obesity: preventing and managing. The global epidemic. 2000. (WHO Technical Report Sseries 894); p. 268.

[2] WHO. Fact sheet: Obesity and overweight. WHO Media centre website. 2016. Available from: http://www.who.int/ mediacentre/factsheets/fs311/en/

[3] Ota T. Chemokine systems link obesity to insulin resistance. Diabetes Metab J. 2013 Jun;37(3):165-172. PubMed PMID: 23807918; PubMed Central PMCID: PMC3689012.

[4] Brown WV, Fujioka K, Wilson PW, et al. Obesity: why be concerned. Am J Med. 2009;122(4 Suppl 1):S4-S11.

[5] Machova L, Cizek L, Koutna J, et al. The impact of obesity on cardiovascular disease mortality in the District Sumperk, Czech Republic. Int J Public Health. 2007;52(4):255-258. PubMed PMID: 18030957.

[6] Karagozian R, Derdak Z, Baffy G. Obesity-associated mechanisms of hepatocarcinogenesis. Metabolism. 2014 May;63(5):607-617. PubMed PMID: 24629562.

[7] Hurt RT, Edakkanambeth Varayil J, Ebbert JO. New pharmacological treatments for the management of obesity. Curr Gastroenterol Rep. 2014;16(6):394. PubMed PMID: 24828101.

[8] Rodgers RJ, Tschop MH, Wilding JP. Anti-obesity drugs: past, present and future. Dis Model Mech. 2012 Sep 5;5:621-626. PubMed PMID: 22915024; PubMed Central PMCID: PMC3424459. 
[9] Lee DR, Lee YS, Choi BK, et al. Roots extracts of Adenophora triphylla var. japonica improve obesity in 3T3-L1 adipocytes and high-fat diet-induced obese mice. Asian Pac J Trop Med. 2015 Nov;8(11):898-906. PubMed PMID: 26614988.

[10] Jo YH, Choi KM, Liu Q, et al. Anti-obesity effect of 6,8diprenylgenistein, an Isoflavonoid of Cudrania tricuspidata fruits in high-fat diet-induced obese mice. Nutrients. 2015 Dec 15;7(12):10480-10490. PubMed PMID: 26694457; PubMed Central PMCID: PMC4690096.

[11] Jeong YJ, Sohn EH, Jung YH, et al. Anti-obesity effect of Crinum asiaticum var. japonicum baker extract in highfat diet-induced and monogenic obese mice. Biomed Pharmacother. 2016 Aug;82:35-43. PubMed PMID: 27470336.

[12] Huang TW, Chang CL, Kao ES, et al. Effect of hibiscus sabdariffa extract on high fat diet-induced obesity and liver damage in hamsters. Food Nutr Res. 2015;59:29018. PubMed PMID: 26475512; PubMed Central PMCID: PMC4608971.

[13] Choi BK, Park SB, Lee DR, et al. Green coffee bean extract improves obesity by decreasing body fat in highfat diet-induced obese mice. Asian Pac J Trop Med. 2016 Jul;9(7):635-643. PubMed PMID: 27393090.

[14] Liu J, Lee J, Salazar Hernandez MA, et al. Treatment of obesity with celastrol. Cell. 2015 May 21;161(5):9991011. PubMed PMID: 26000480; PubMed Central PMCID: PMC4768733.

[15] Qin L, Ou-Yang L-B. Anti-obesity effect of glycyrrhizin on obese rats and its mechanism. Cent Pharm. 2010;8:204-208.

[16] Xie W, Zhang Y, Wang N, et al. Novel effects of macrostemonoside A, a compound from Allium macrostemon Bung, on hyperglycemia, hyperlipidemia, and visceral obesity in high-fat diet-fed C57BL/6 mice. Eur J Pharmacol. 2008;599(1-3):159-165.

[17] Cheng J, Zhou ZW, Sheng HP, et al. An evidence-based update on the pharmacological activities and possible molecular targets of Lycium barbarum polysaccharides. Drug Des Devel Ther. 2015;9:33-78. PubMed PMID: 25552899; PubMed Central PMCID: PMC4277126.

[18] Xiao-Xu G, Xian-Jun M, Ji-Hai L. Study on functions of active polysaccharide from Schisandra Chinensis (Turcz) Baill in reducing weight and fat. Sci Technol Food Ind. 2008;29:248-251.

[19] Wei-Wei L, Jin Y, Li-Hua W, et al. Effect of hawthorn leaf flavonids on lipid metabolism in hyperlipidemia rats. Health Res. 2010;8:8-11.

[20] Zhang WL, Zhu L, Jiang JG. Active ingredients from natural botanicals in the treatment of obesity. Obes Rev. 2014 Dec;15(12):957-967. PubMed PMID: 25417736.

[21] Kim KS, Lee DS, Bae GS, et al. The inhibition of JNK MAPK and NF-kappaB signaling by tenuifoliside A isolated from Polygala tenuifolia in lipopolysaccharideinduced macrophages is associated with its anti-inflammatory effect. Eur J Pharmacol. 2013 Dec 05;721(13):267-276. PubMed PMID: 24076326.

[22] Jin ZL, Gao N, Zhang JR, et al. The discovery of Yuanzhi-1, a triterpenoid saponin derived from the traditional Chinese medicine, has antidepressant-like activity. Prog Neuropsychopharmacol Biol Psychiatry. 2014 Aug 4;53:9-14. PubMed PMID: 24614095.
[23] Liu P, Hu Y, Guo DH, et al. Potential antidepressant properties of Radix Polygalae (Yuan Zhi). Phytomedicine. 2010 Aug;17(10):794-799. PubMed PMID: 20541923.

[24] The State Commission of Chinese Pharmacopoeia. Pharmacopoeia of People's Republic of China, part I. Beijing: Chemical Industry Press; 2010.

[25] Lee H, Kang R, Yoon Y. SH21B, an anti-obesity herbal composition, inhibits fat accumulation in 3T3-L1 adipocytes and high fat diet-induced obese mice through the modulation of the adipogenesis pathway. J Ethnopharmacol. 2010 Feb 17;127(3):709-717. PubMed PMID: 19963057.

[26] Lee JH, Kim T, Lee JJ, et al. The herbal medicine KBH-1 inhibits fat accumulation in 3T3-L1 adipocytes and reduces high fat diet-induced obesity through regulation of the AMPK pathway. PLoS One. 2015;10(12): e0142041. PubMed PMID: 26649747; PubMed Central PMCID: PMC4674115.

[27] Lee JH, Lee JJ, Cho WK, et al. KBH-1, an herbal composition, improves hepatic steatosis and leptin resistance in high-fat diet-induced obese rats. BMC Complement Altern Med. 2016 Sep 13;16:355-367. PubMed PMID: 27618865; PubMed Central PMCID: PMC5020448.

[28] Everard A, Cani PD. Diabetes, obesity and gut microbiota. Best Pract Res Clin Gastroenterol. 2013 Feb;27 (1):73-83. PubMed PMID: 23768554.

[29] Robles Alonso V, Guarner F. Linking the gut microbiota to human health. Br J Nutr. 2013 Jan;109(Suppl 2):S21S26. PubMed PMID: 23360877.

[30] Human Microbiome Project C. Structure, function and diversity of the healthy human microbiome. Nature. 2012 Jun 13;486(7402):207-214. PubMed PMID: 22699609; PubMed Central PMCID: PMC3564958.

[31] Jin Y, Zeng Z, Wu Y, et al. Oral exposure of mice to carbendazim induces hepatic lipid metabolism disorder and gut microbiota dysbiosis. Toxicological Sci. 2015 Sep;147(1):116-126. PubMed PMID: 26071454.

[32] Lin H, An Y, Hao F, et al. Correlations of fecal metabonomic and microbiomic changes induced by high-fat diet in the pre-obesity state. Sci Rep. 2016 Feb 26;6:21618. PubMed PMID: 26916743; PubMed Central PMCID: PMC4768318.

[33] Everard A, Lazarevic V, Derrien M, et al. Responses of gut microbiota and glucose and lipid metabolism to prebiotics in genetic obese and diet-induced leptinresistant mice. Diabetes. 2011;60(11):2775-2786.

[34] Clarke SF, Murphy EF, Nilaweera K, et al. The gut microbiota and its relationship to diet and obesity: new insights. Gut Microbes. 2012 May-Jun;3(3):186202. PubMed PMID: 22572830; PubMed Central PMCID: PMC3427212.

[35] Mai V, McCrary QM, Sinha R, et al. Associations between dietary habits and body mass index with gut microbiota composition and fecal water genotoxicity: an observational study in African American and Caucasian American volunteers. Nutr J. 2009;21(8):49-59.

[36] Arumugam M, Raes J, Pelletier E, et al. Enterotypes of the human gut microbiome. Nature. 2011 May 12;473 (7346):174-180. PubMed PMID: 21508958; PubMed Central PMCID: PMC3728647.

[37] Chakraborti CK. New-found link between microbiota and obesity. World J Gastrointest Pathophysiol. 2015 
Nov 15;6(4):110-119. PubMed PMID: 26600968; PubMed Central PMCID: PMC4644874.

[38] Moreno-Indias I, Cardona F, Tinahones FJ, et al. Impact of the gut microbiota on the development of obesity and type 2 diabetes mellitus. Front Microbiol. 2014;5 (190):1-10. PubMed PMID: 24808896; PubMed Central PMCID: PMC4010744.

[39] Graham C, Mullen A, Whelan K. Obesity and the gastrointestinal microbiota: a review of associations and mechanisms. Nutr Rev. 2015 Jun;73(6):376-385. PubMed PMID: 26011912.

[40] Zebisch K, Voigt V, Wabitsch M, et al. Protocol for effective differentiation of 3T3-L1 cells to adipocytes. Anal Biochem. 2012 Jun 01;425(1):88-90. PubMed PMID: 22425542.

[41] Shackelford CYNTHIA, Long G, Wolf JEFFREY, et al. Qualitative and quantitative analysis of nonneoplastic lesions in toxicology studies. Toxicol Pathol. 2002;30 (1):93-96.

[42] Garber M, Grabherr MG, Guttman M, et al. Computational methods for transcriptome annotation and quantification using RNA-seq. Nat Methods. 2011 Jun;8(6):469-477. PubMed PMID: 21623353.

[43] Shin J, Lee S, Go MJ, et al. Analysis of the mouse gut microbiome using full-length $16 \mathrm{~S}$ rRNA amplicon sequencing. Sci Rep. 2016 Jul 14;6:29681. PubMed PMID: 27411898; PubMed Central PMCID: PMC4944186.

[44] Marmugi A, Ducheix S, Lasserre F, et al. Low doses of bisphenol A induce gene expression related to lipid synthesis and trigger triglyceride accumulation in adult mouse liver. Hepatology. 2012 Feb;55(2):395-407. PubMed PMID: 21932408.

[45] Million M, Lagier JC, Yahav D, et al. Gut bacterial microbiota and obesity. Clinical Microbiol Infection. 2013 Apr;19(4):305-313. PubMed PMID: 23452229.

[46] Saito T, Nishida M, Saito $M$, et al. The fruit of Acanthopanax senticosus (Rupr. et Maxim.) Harms improves insulin resistance and hepatic lipid accumulation by modulation of liver adenosine monophosphateactivated protein kinase activity and lipogenic gene expression in high-fat diet-fed obese mice. Nutr Res. 2016 Oct;36(10):1090-1097. PubMed PMID: 27865350.

[47] Echeverria F, Ortiz M, Valenzuela R, et al. Long-chain polyunsaturated fatty acids regulation of PPARs, signaling: relationship to tissue development and aging. Prostaglandins Leukot Essent Fatty Acids. 2016 Nov;114:28-34. PubMed PMID: 27926461.

[48] Ip E, Farrell GC, Robertson G, et al. Central role of PPARalpha-dependent hepatic lipid turnover in dietary steatohepatitis in mice. Hepatology. 2003 Jul;38(1):123132. PubMed PMID: 12829994.

[49] Rakhshandehroo M, Sanderson LM, Matilainen M, et al. Comprehensive analysis of PPARalpha-dependent regulation of hepatic lipid metabolism by expression profiling. PPAR Res. 2007;2007:26839. PubMed PMID: 18288265; PubMed Central PMCID: PMC2233741.

[50] Dwyer JR, Donkor J, Zhang P, et al. Mouse lipin-1 and lipin-2 cooperate to maintain. PNAS. 2012.

[51] Kang HW, Wei J, Cohen DE. Regulation of lipid and glucose metabolism by phosphatidylcholine transfer protein. Trends Endocrinol Metab. 2010 Jul;21(7):449456. PubMed PMID: 20338778; PubMed Central PMCID: PMC2897958.
[52] Wang J, Mitsche MA, Lutjohann D, et al. Relative roles of ABCG5/ABCG8 in liver and intestine. J Lipid Res. 2015 Feb;56(2):319-330. PubMed PMID: 25378657; PubMed Central PMCID: PMC4306686.

[53] Kamisuki S, Mao Q, Abu-Elheiga L, et al. A small molecule that blocks fat synthesis by inhibiting the activation of SREBP. Chem Biol. 2009 Aug 28;16 (8):882-892. PubMed PMID: 19716478.

[54] Zhu X, Bian H, Gao X. The potential mechanisms of berberine in the treatment of nonalcoholic fatty liver disease. Molecules. 2016 Oct 14;21(10). PubMed PMID: 27754444. DOI:10.3390/molecules21101336

[55] Nukitrangsan N, Iwasaki H, Okabe T, et al. Effect of Peucedanum japonicum Thunb on the expression of obesity-related genes in mice on a high-fat diet. J Oleo Sci. 2011;60(10):527-536.

[56] Olteanu S, Kandel-Kfir M, Shaish A, et al. Lack of interleukin-1alpha in Kupffer cells attenuates liver inflammation and expression of inflammatory cytokines in hypercholesterolaemic mice. Digestive Liver Dis. 2014 May;46(5):433-439. PubMed PMID: 24582082.

[57] Szabo G, Csak T. Inflammasomes in liver diseases. J Hepatol. 2012 Sep;57(3):642-654. PubMed PMID: 22634126.

[58] Negrin KA, Roth Flach RJ, DiStefano MT, et al. IL-1 signaling in obesity-induced hepatic lipogenesis and steatosis. PloS One. 2014;9(9):e107265. PubMed PMID: 25216251; PubMed Central PMCID: PMC4162604.

[59] Osborn O, Brownell SE, Sanchez-Alavez M, et al. Treatment with an Interleukin 1 beta antibody improves glycemic control in diet-induced obesity. Cytokine. 2008 Oct;44(1):141-148. PubMed PMID: 18723371; PubMed Central PMCID: PMC3063393.

[60] Trigueros L, Peña S, Ugidos AV, et al. Food ingredients as anti-obesity agents. Crit Rev Food Sci Nutr. 2013;53 (9):585-587.

[61] Patterson E, Ryan PM, Cryan JF, et al. Gut microbiota, obesity and diabetes. Postgrad Med J. 2016 May;92 (1087):286-300. PubMed PMID: 26912499.

[62] Wong JM, de Souza R, Kendall CW, et al. Colonic health: fermentation and short chain fatty acids. J Clin Gastroenterol. 2006 Mar;40(3):235-243. PubMed PMID: 16633129.

[63] Semova I, Carten JD, Stombaugh J, et al. Microbiota regulate intestinal absorption and metabolism of fatty acids in the zebrafish. Cell Host Microbe. 2012 Sep 13;12(3):277-288. PubMed PMID: 22980325; PubMed Central PMCID: PMC3517662.

[64] Clarke SF, Murphy EF, O'Sullivan O, et al. Targeting the microbiota to address diet-induced obesity: a time dependent challenge. PLoS One. 2013;8(6):e65790. PubMed PMID: 23762426; PubMed Central PMCID: PMC3676335.

[65] Looft T, Johnson TA, Allen HK, et al. In-feed antibiotic effects on the swine intestinal microbiome. Proc Natl Acad Sci USA. 2012 Jan 31;109(5):1691-1696. PubMed PMID: 22307632; PubMed Central PMCID: PMC3277147.

[66] Kameyama K, Itoh K. Intestinal colonization by a Lachnospiraceae bacterium contributes to the development of diabetes in obese mice. Microbes Env. 2014;29 (4):427-430. PubMed PMID: 25283478; PubMed Central PMCID: PMC4262368. 
[67] Kim KA, Gu W, Lee IA, et al. High fat diet-induced gut microbiota exacerbates inflammation and obesity in mice via the TLR4 signaling pathway. PLoS One. 2012;7(10):e47713. PubMed PMID: 23091640; PubMed Central PMCID: PMC3473013.
[68] Evans CC, LePard KJ, Kwak JW, et al. Exercise prevents weight gain and alters the gut microbiota in a mouse model of high fat diet-induced obesity. PLoS One. 2014;9(3):e92193. PubMed PMID: 24670791; PubMed Central PMCID: PMC3966766. 